\title{
2005 Alzheimer Award
}

The Associate Editors of JAD selected the best article from Volume 6 as the recipient of the Alzheimer Medal. The 2005 joint winners of the Alzheimer Award, sponsored by Elan Pharmaceuticals, were Hideo Hara, M.D. and Takeshi Tabira, M.D., Ph.D. for their article "Development of a safe oral $\mathrm{A} \beta$ vaccine using recombinant adeno-associated virus vector for Alzheimer's disease" (J Alzheimers Dis 6, 483-488, 2004).

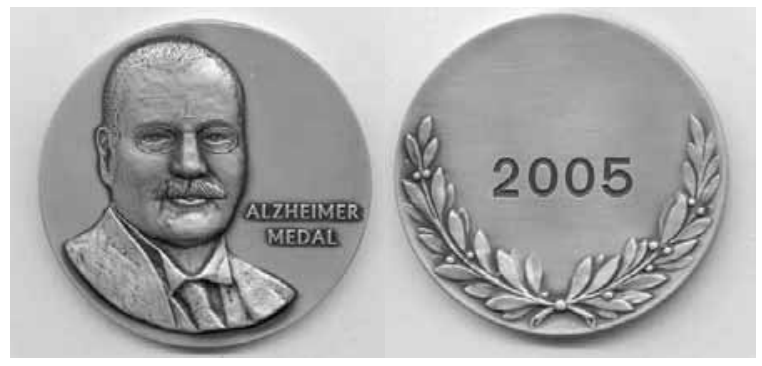

\section{Awardees}

Hideo Hara, M.D. and Takeshi Tabira, M.D., Ph.D.

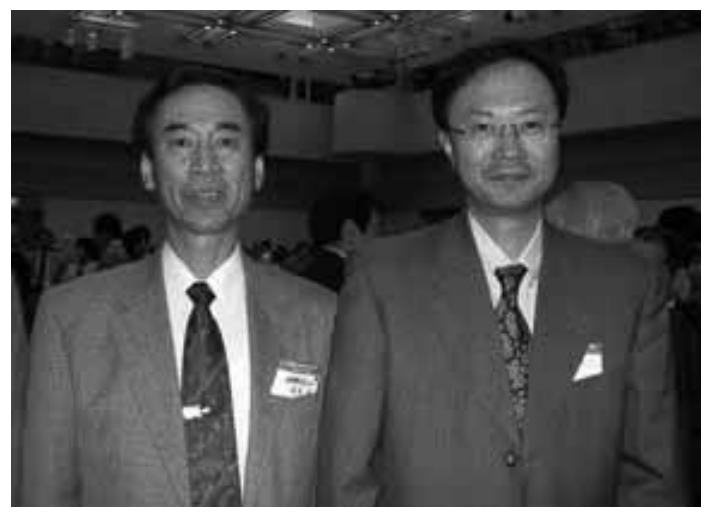

Hideo Hara, M.D., graduated from the Faculty of Medicine, Kyushu University, Japan in 1983 and received a Ph.D. in 1990 from same university. While doing clinical work in the Department of Neurology at Kyushu University hospital, Dr. Hara developed an interest in neuroimmunology and investigated the $\mathrm{T}$ cell receptor repertoire of the CNS infiltrated lymphocytes of multiple sclerosis and HAM/TSP patients. In 1999, Dr. Hara was appointed Section Chief of the Department of Demyelinating Diseases and Aging at the National Institute of Neuroscience, NCNP, Japan. Since that time, Drs. Hara and Tabira have worked to develop immunotherapy for Alzheimer's disease based on their knowledge of neuroimmunology.

Takeshi Tabira, M.D., Ph.D., President of the 8th International Congress of Neuroimmunology in 2006, has been studying multiple sclerosis and other neuroimmunological diseases. He has also conducted numerous high profile studies in Alzheimer disease. Since he is an expert in neuroimmunology, it was natural for him to think of the oral vaccine. He knew that the gut immune system suppresses Th1 and enhances Th2 immune responses. The vaccine-mediated encephalomyelitis is thought to be mediated by Th1-type $\mathrm{T}$ cells so this route of treatment could diminish side effects.

\section{Importance of published article}

The work presented in the paper "Development of a safe oral $\mathrm{A} \beta$ vaccine using recombinant adenoassociated virus vector for Alzheimer's disease" (JAD 6: $483-488,2004)$ was performed by Dr. H. Hara at the National Institute for Longevity Sciences, NCGG, Aichi, Japan.

The paper presents a new oral vaccine treatment for Alzheimer's disease using adeno-associated virus (AAV) vector carrying A $\beta$ cDNA. The treatment is quite effective for ameliorating Alzheimer's disease pathology in mice. Immunotherapy is still a promising therapeutic approach for Alzheimer's disease regardless of the reported side effects of the phase IIa trial of AN1792(QS-21). This new oral vaccine does not induce strong Th1 T cell immune reactions, and hence it could reduce the side effects of such meningoencephalitis. 